\title{
The impact of a research elective on a respiratory therapy student's perspective
}

\author{
Nikolay Moroz, MD, SRT ${ }^{1}$, Marco Zaccagnini, RRT/CCAA, BHSc, MSc (c)², Thomas Piraino, RRT, FCSRT ${ }^{3}$
}

N Moroz, M Zaccagnini, T Piraino. The impact of a research elective on a respiratory therapy student's perspective. Can J Respir Ther 2019;55:36-39. doi: $10.29390 /$ cjrt-2019-003.

\begin{abstract}
As the infrastructure of the healthcare landscape continues to change, Registered Respiratory Therapists (RRTs) may be required to assume nontraditional roles in health care. One such role is RRTs as researchers. However, there are few opportunities for students to explore research as a career option given current rigidly structured didactic curriculums. One possible solution to this dilemma is the addition of a summertime research elective. The following article will discuss the general importance of research, followed by an overview of RRTs involved in research. We conclude this article with a narrative recount of an RRT researcher and a respiratory therapy student's initiative to organize and execute a summertime research elective.
\end{abstract}

Key Words: research; elective; student; respiratory therapy; education

\section{INTRODUCTION}

Registered Respiratory Therapists (RRTs) in Canada graduate from academic and clinical programs that provide entry-to-practice education for the respiratory therapy profession. Various types of educational institutions offer these programs and utilize didactic learning components to prepare students for clinical training in acute and community settings [1]. The didactic component is typically delivered over a span of 2 years (six academic terms), while the clinical practicum is typically a single year in length (three academic terms). To fully transition from student to an RRT, students must complete board certified licensure as a graduate from an accredited institution. Following this transition, many RRTs begin careers at the same sites where they did their clinical training [2]. However, because of the ever-changing landscape of the modern health care system, many practicing RRTs find themselves filling in roles that do not usually fall within the framework of traditional practice. In the probable future, RRTs will be expected to fill some of these nontraditional roles, and one potentially important area where respiratory therapist roles might change is in research [2-4]. Respiratory therapy-focused research is expanding, and as it expands the need for qualified RRT contributors will undoubtedly grow [4]. To date, however, anecdotal observations suggest that only a small percentage of RRTs are working as researchers. To meet future demands the knowledge and skills pertaining to research design, evidence-based practice, and scientific literacy would need to be expanded across didactic components of training programs [5-7]. Although the National Competency Framework for Professional Respiratory Therapy currently requires accredited institutions to include some instruction in the research enterprise, the level of competency obtained is often low, and many RRTs with interest in research find themselves lacking the knowledge, experience, and confidence to pursue research as a career.
The question then arises: within oftentimes rigidly structured training programs, how can interested respiratory therapy students gain exposure to RRT research? Currently, there is a lack of literature focusing on respiratory therapy students who undertake a research elective during their academic training. As such, one possible solution to increase research exposure is the addition of a summertime student research observership elective. This article will discuss the importance of research for the respiratory therapist, the current attitudes of RRTs around research, and a student-mentor led experience in an elective research opportunity.

\section{Importance of research}

Clinical research is the study of health and illness in people. It is the way we generate knowledge that supports the prevention, diagnosis, and treatment of disease and improves wellbeing [8-10]. Today, clinical research practice follows a defined scientific process intended to ensure enquiry is grounded in measurable and confirmable practices (Figure 1). The process consists of developing a hypothesis or research question, a method for exploring the research question, and the translation of knowledge into practice. Describing the impact of respiratory care research on the lives of people is beyond the scope of this paper but has been articulated by others [11, 12].

The scientific process and its products are just one piece of the larger clinical reality. As practicing clinicians, we also rely on accumulated clinical expertise, education, and clinical skills while taking into consideration the patient's values, expectations, and unique concerns. When we apply the scientific method to our daily clinical practice, we are providing our patients with evidence-based practice (EBP). Sackett [13] defines EBP as the conscientious, explicit, and judicious use of current best evidence to make the most appropriate decisions about the care of the

${ }^{1}$ Respiratory $\mathbb{E}$ Anaesthesia Program, Vanier College, Saint-Laurent, QC, Canada

${ }^{2}$ Department of Anesthesia $\mathcal{E}$ Critical Care, McGill University Health Centre, Montréal, QC, Canada

${ }^{3}$ Centre of Excellence in Mechanical Ventilation, St. Michael's Hospital, Toronto, ON, Canada and Department of Anesthesia Division of Critical Care, McMaster University, Hamilton, ON, Canada

Correspondence: Marco Zaccagnini, Department of Anesthesia $\mathcal{E}$ Critical Care, McGill University Health Centre, Royal Victoria $\mathcal{E}$ Montréal General Hospital, 1001 Decarie Blvd, Montreal, QC H4A 3J1, Canada. Tel.: (514) 969-7204. E-mail: marco.zaccagnini@mcgill.ca

Published online at https://www.cjrt.ca on 01 April 2019 


\section{FIGURE 1}

The steps of the scientific method [37].

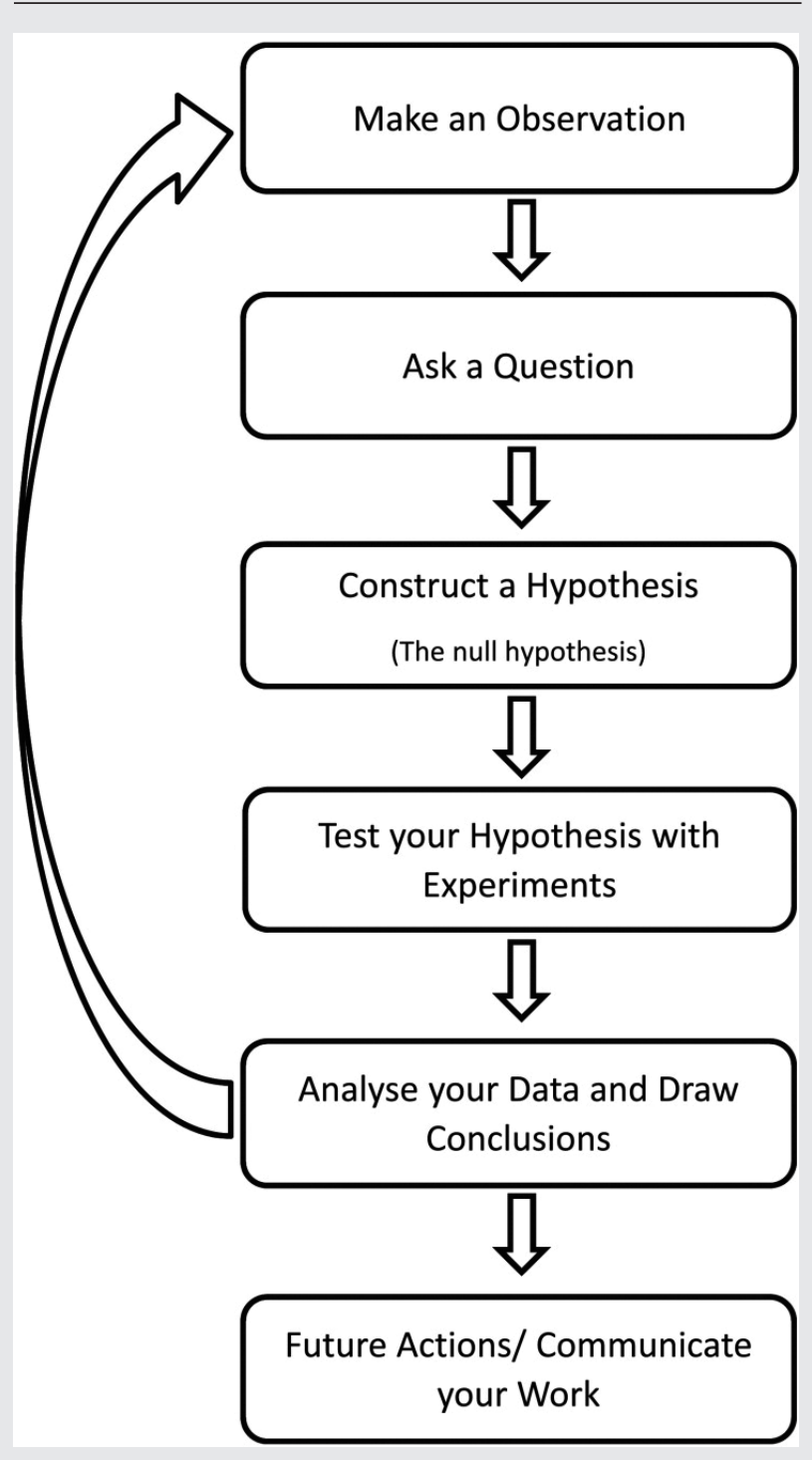

individual patient. Clinical respiratory care research has an impact on the way care is delivered to our patients. The cornerstone of EBP is clinical research, and with more RRTs influencing the types of research questions being investigated, the more that respiratory care itself will be improved [14].

\section{Research for student respiratory therapists (SRTs)}

In traditional lecture-based learning, discussions are initiated in the classroom and students tend to reiterate academic lecture material for evaluative purposes [15]. Although many students achieve scholarly successes using these methods, they may not be adequate to succeed as an evidence-based practitioner. EBP is based on a systematic approach to decision-making in response to ever-increasing complex patient care and an influx of available medical literature [16-18]. Evaluating existent literature and conducting research is the norm in undergraduate, [19] graduate, and medical school curriculums [20-24]. Boyle's study [25] with medical students showed that early exposure of medical students to the realm of research motivated them to participate in research activities after graduation and helped provide students with skills in leadership, teamwork, presentation, analytic skills, and research presentation [25]. These same outcomes might be expected in student respiratory therapists who gain research experience during training. There is no doubt that RRTs should be able to read and critically analyze scientific articles related to their area of practice since it is a core competency of all SRTs $[12,26]$. In this way, research experience will be useful for future RRTs since it will provide a better understanding of research techniques and data interpretation.

\section{Respiratory therapists in research}

Respiratory disease is the third leading cause of death and disability globally, accounting for one-fifth of all deaths, leading to an economic burden in excess of $\$ 100$ billion per year [27]. These statistics arguably highlight the critical need for increased research in the respiratory care field. In this regard RRTs have much to offer, as individuals who work with respiratory disease patients RRTs have important perspectives on the approach to clinical problems and proposed solutions. RTs have extensive education in the field of pulmonary physiology and mechanical ventilation, which gives them unique insight into the types of care gaps that pulmonary research should strive to address [28]. In the Canadian context, a survey indicated that RRTs have a strong willingness to conduct and participate in research and that they believe RRTs are better suited than nurses or physicians to conduct respiratory therapyrelated research [29]. However, one of the main factors limiting their participation in research is the level of exposure to research during their education. This is exemplified by the fact that only $2.9 \%$ of respondents surveyed indicated that they were expecting to participate in research, as part of their job, after graduation [29]. Most practitioners have simultaneous roles such caring for patients, teaching students, and managing a department, but very few people are serving as researchers [30]. The lack of RRT researchers is not a new concern, as a 2004 editorial from the American Association of Respiratory Care echoes the concerns discussed among many in positions of leadership, "Where will the next generation of respiratory therapist researchers come from?" [30]. Confounding the above is the fact that there exist only a handful of publications aimed at supporting individuals working in respiratory care research [31-33]. Collectively these facts suggest that, if future RRTs are to become more active in research, there must be greater effort to create opportunities that introduce its values and processes during student training.

\section{Student experience}

A working example of such an opportunity is provided by the co-author of this article (NM) who sought out and participated in a summertime research elective (observership). The goal of the observership was to learn about the role of an RRT in respiratory research. St. Michael's Hospital in Toronto, Ontario, is one of the top 40 research hospitals in Canada (\#12 for 2017 and 2018) [34]. They have also started the Centre of Excellence in Mechanical Ventilation (CoEMV) in Toronto, and this was central to the observership because they employ an RRT as both a staff member and a lab researcher $[35,36]$.

This observership opportunity derived from an introduction between the clinical researcher RRT at CoEMV and NM. The introduction was made through a mutual colleague (MZ) during a professional networking opportunity. The student subsequently emailed the researcher RRT outlining the goals of his proposed observership and his curriculum vitae. After receiving approval from the RRT, the Principal Investigator of the lab was contacted to get final approval for the observership.

The observership consisted of participating in different research and education activities organized in the CoEMV by shadowing the research RRT for 1 week. The observership provided a unique opportunity to gain real-world perspective that an RRT researcher experiences in the modern health care system. Additionally, the experience indicated the importance of research in modern respiratory therapy. Research is an essential part of the development of the practice of respiratory care and, therefore, it is vital that SRTs and RRTs experience research as a part of their academic and professional careers. The participation in research 
allows the SRT to not only to improve knowledge and skills in the field but also to advance patient care. Knowledge related to mechanical ventilation, gained during the observership, supported better understanding of related concepts when they arose in the school curriculum (e.g., concepts pertaining to waveform analysis, esophageal pressure monitoring, and asynchrony identification). Overall, the week of observership met NM's goal of understanding the role of an RT as a researcher.

\section{Preceptor experience}

The level of clinical research that a student is exposed to or can participate in depends solely on the specifics of the clinical site in which they are working. However, the clinical site may not be involved in research associated particularly with the skills and knowledge most common for RRTs (i.e., mechanical ventilation, pulmonary function, resuscitation, etc.). When approached by NM regarding observership, the researcher (TP) was intrigued not only by the initiative taken by an SRT but also the realization of how this experience might benefit a student interested in research. St. Michael's Hospital in Toronto, Ontario, has positioned itself as a CoEMV along with other academic hospitals in Toronto to ensure evidence-based mechanical ventilation is not only being practiced but also created through research and innovation. Regarding the involvement of RRTs with mechanical ventilation research, St. Michael's Hospital strives to be exemplary, as evidenced by their immediate recruitment of necessary resources to create and execute the observership with efficiency and timeliness. There is always regular discussion of research for both ongoing and future projects, evolving research ethics board processes, retrospective data collection, consenting and enrolling participants, and performing of study protocols.

It was an excellent opportunity to showcase not only the work being done in a research lab dedicated to mechanical ventilation but also to witness the dedication to research exhibited by the bedside clinicians, with whom NM was also able to discuss the process involved in creating and conducting their own research.

The experience for the mentor was one of optimism that an SRT is interested and eager to learn how they could be involved with and even conduct their own research. The involvement of RRTs in clinical research is essential for moving our profession forward and ensuring optimal care for our patients. The thirst for knowledge should follow the SRT through their transition to RRT but leading the initiative and promoting involvement is essential in this.

\section{Future work}

The authors hope is that this report of a single student's observership elective will inspire other students to seek similar opportunities. NM greatly enjoyed the observership, he learned about a unique facet of the respiratory profession and also met many different clinicians with a variety of backgrounds-their commonality was their desire to forward respiratory care as a science. To facilitate this experience, the authors suggest beginning a conversation with your academic and professional network to identify potential RRT researchers. It is essential to approach a mentor with a singular intent and clear objectives for the elective experience. Outlining ones objectives and research interests will help identify mentors who may have expertise in research outside that of the traditional RRT framework (i.e., research in public policy, education, etc.). Additionally, RRTs who are suited to be research mentors should be identified and potentially compensated for their time and effort in student observership. Further research may involve a narrative study of students who have completed research electives to understand their desire to do so, survey data to quantify the number of RRTs who work in a research capacity, and a scoping review to map the literature on student observerships and better understand their benefits.

\section{CONCLUSION}

Research is essential in driving the RRT profession forward since applying research and evidence to our practice ensures the most up-to-date care for our patients. Dedicated research has become mandatory in almost all levels of academia to teach students how to properly navigate the surplus of available literature with a critical eye. Exposure to research has the potential to spark student's interest, creating enthusiasm that may lead them to pursue research as a career. The question becomes centered on integrating SRTs in the world of research. This article describes the unique experience of an RRT preceptor and SRT who participated in a summer elective observership in a clinical research site with a dedicated research RRT. The experience showed the student the importance of research in respiratory therapy and provided the motivation to consider research as an important part of practice while transitioning into an independent working professional.

\section{ACKNOWLEDGMENTS}

We would like to thank Laurent J. Brochard, MD, and Kari White, RRT, FCSRT, for the help in organizing and conducting the observership. Also, we are grateful to the peer-reviewers for their invaluable time and wisdom.

\section{REFERENCES}

1. Canadian Society of Respiratory Therapists. How do I become a respiratory therapist? [Internet]. 2018. Available at: https://www.csrt.com/ rt-profession/\#becomeart (Accessed October 08, 2018).

2. Canadian Society of Respiratory Therapists. What is a respiratory therapist? [Internet]. 2018. Available at: https://www.csrt.com/rt-profession/ (Accessed October 08, 2018).

3. Myers TR. Thinking outside the box: Moving the respiratory care profession beyond the hospital walls. Respir Care 2013;58(8): 1377-85. doi: 10.4187/respcare.02542.

4. Barnes TA, Kacmarek RM, Kageler WV, Morris MJ, Durbin CG, Jr. Transitioning the respiratory therapy workforce for 2015 and beyond. Respir Care 2011;56(5): 681-90. doi: 10.4187/respcare.01169.

5. The Michener Institute of Education at UHN. Respiratory therapy curriculum [Internet]. Available at: https://michener.ca/academicprograms/michener/respiratory-therapy-curriculum/ (Accessed October 08, 2018).

6. Algonquin College. Respiratory therapy [Internet]. 2018. Available at: http://www.algonquincollege.com/programdocs/0606X01FWO.pdf (Accessed October 08, 2018).

7. Vanier College. Course description [Internet]. 2018. Available at: http:// www.vaniercollege.qc.ca/respiratory-anaesthesia/course-description/ (Accessed October 08, 2018).

8. Sacristan JA. Clinical research and medical care: Towards effective and complete integration. BMC Med Res Methodol 2015;15: 4. doi: $10.1186 / 1471-2288-15-4$.

9. Harvard Library. Countway library guide to participating in health research [Internet]. 2017. Available at: https://guides.library.harvard. edu/healthresearch (Accessed October 08, 2018).

10. University of Virginia School of Medicine. What is clinical research? [Internet]. 2018. Available at: https://research.med.virginia.edu/ clinicalresearch/participate-in-a-trial/what-is-medical-research/ (Accessed December 09, 2018).

11. Bhatt A. Evolution of clinical research: A history before and beyond James Lind. Perspect Clin Res 2010;1(1): 6-10.

12. Chatburn RL. Overview of respiratory care research. Respir Care 2004; 49(10): 1149-56

13. Sackett DL, Rosenberg WMC, Gray JAM, Haynes RB, Richardson WS. Evidence based medicine: What it is and what it isn't. BMJ (Clinical research ed 1996;312(7023): 71-2. doi: 10.1136/bmj.312.7023.71.

14. Schwenzer KJ, Durbin CG, Jr. The spectrum of respiratory care research: Prospective clinical research. Respir Care 2004;49(10): 1165-70.

15. McCarthy JP, Anderson L. Active learning techniques versus traditional teaching styles: Two experiments from history and political science. Innov High Educ 2000;24(4): 279-94. doi: 10.1023/B:IHIE.0000047415. 48495.05 .

16. Bero LA, Grilli R, Grimshaw JM, Harvey E, Oxman AD, Thomson MA. Closing the gap between research and practice: An overview of systematic reviews of interventions to promote the implementation of research findings. The Cochrane Effective Practice and Organization of Care Review Group. BMJ (Clinical research ed) 1998;317(7156): 465-8. doi: 10.1136/ bmj.317.7156.465.

17. Alper BS, Hand JA, Elliott SG, et al. How much effort is needed to keep up with the literature relevant for primary care?. J Med Libr Assoc 2004;92(4): 429-37. 
18. Mallett S, Clarke M. How many Cochrane reviews are needed to cover existing evidence on the effects of health care interventions?. ACP J Club 2003;139(1): A11.

19. Ash Merkel C. Undergraduate research at the research universities. New Directions Teach Learn 2003;2003(93): 39-54. doi: 10.1002/tl.87.

20. Springer JR, Baer LJ. Instruction in research-related topics in US and Canadian medical schools. J Med Educ 1988;63(8): 591-5

21. Harasym PH, Mandin H, Sokol PA, Lorscheider FL. Development of a research elective program for first-and second-year medical students. Teach Learn Med 1992;4(3): 173-9. doi: 10.1080/10401339209539558.

22. Pathipati AS, Taleghani N. Research in medical school: A survey evaluating why medical students take research years. Cureus 2016;8(8): e741. doi: $10.7759 /$ cureus. 741 .

23. Small AC, Levy LL. In support of medical student research. Acad Med 2013;88(11): 1592. doi: 10.1097/ACM.0b013e3182a7fa30.

24. Laidlaw A, Aiton J, Struthers J, Guild S. Developing research skills in medical students: AMEE Guide No. 69. Med Teach 2012;34(9): e754-71. doi: 10.3109/0142159X.2012.704438.

25. Boyle SE, Cotton SC, Myint PK, Hold GL. The influence of early research experience in medical school on the decision to intercalate and future career in clinical academia: A questionnaire study. BMC Med Educ 2017;17(1): 245. doi: 10.1186/s12909-017-1066-1.

26. The National Alliance of Respiratory Therapy Regulatory Bodies. National competency framework for the profession of respiratory therapy [Internet]. 2016. Available at: http://nartrb.ca/download/ncf-part-i-entry-to-practice-2016/?wpdmdl=33 (Accessed October 08, 2018).

27. European Respiratory Society. Respiratory diseases in the world [Internet]. 2013. Available at: https://www.ersnet.org/pdf/publications/ firs-world-report.pdf (Accessed October 08, 2018).
28. American Association for Respiratory Care. Why respiratory care research is the right job for me [Internet]. 2018. Available at: http://www. aarc.org/careers/career-advice/professional-development/respiratorycare-research-right-job/ (Accessed October 08, 2018).

29. Martins C, Kenaszchuk C. Research capacity of respiratory therapists: A survey of views, opinions and barriers. Can J Respir Ther 2013;49(4): 15-9.

30. Pierson DJ. Research and publication in respiratory care. Respir Care 2004;49(10): 1145-8.

31. Chatburn RL, Craig KC. Fundamentals of respiratory care research. East Norwalk, Connecticut: Appleton and Lange; 1988.

32. Chatburn R. Handbook for respiratory care research. Cleveland: Cat in the Dark Productions; 2002. p. 260-71.

33. Tiffin N. Evaluating medical research and statistics. What every respiratory therapist needs to know. 3rd edn. Available at: http://www.tiffin. ca/buythebook.shtml. (Accessed March 18, 2019.)

34. RE $\$ E A R C H$ Infosource Inc. Canada's top 40 research hospitals 2018 [Internet]. 2018. Available at: https://researchinfosource.com/top-40-research-hospitals/2018/list (Accessed December 09, 2018).

35. St. Michael's Hospital. Dr. Laurent Brochard's Lab [Internet]. 2018. Available at: http://stmichaelshospitalresearch.ca/labs/laurent-brochard/ (Accessed December 09, 2018).

36. The Toronto Centre of Excellence in Mechanical Ventilation. The CoEMV Blog [Internet]. 2018. Available at: https://coemv.ca/ (Accessed October 08, 2018).

37. Yeoman K, Bowater L, Nardi E. The representation of scientific research in the national curriculum and secondary school pupils' perceptions of research, its function, usefulness and value to their lives. F1000Res 2016;4: 1442. doi: 10.12688/f1000research.7449.2. 